\title{
Pharmaceutical Marketing to Medical Students: The Student Perspective
}

\author{
Joseph Barfett*, Brent Lanting, Julian Lee, MSc, Michael Lee, MSc, \\ Victor Ng, BSc, Peter Simkhovitch, BSc
}

\begin{abstract}
It has been estimated that pharmaceutical companies spend $\$ 1.7$ billion every year promoting their products to physicians in Canada. At least \$21 billion are spent every year on drug promotion in the United States. Although pharmaceutical marketing campaigns are primarily directed toward practicing physicians and residents, medical students are targeted as well. The goal of this study was to assess medical student attitudes toward pharmaceutical promotion in a Canadian academic centre. A questionnaire was designed to assess the attitudes of medical students about pharmaceutical promotion, including the acceptability of receiving various gifts and incentives. The survey was administered to first, second, and fourth-year medical students at the University of Western Ontario (London, Ontario, Canada). Statistical methods were employed to compare subpopulations of students based on demographic and socioeconomic data. Some $81 \%$ of students were not opposed to interacting with drug companies in medical school. Medical students felt comfortable accepting gifts of low monetary value, such as lunches $\mathbf{( 7 5 \% )}$ ) and penlights $\mathbf{7 4 \%}$ ), but were willing to accept gifts of higher monetary value if the gifts served an educational purpose, such as textbooks (65\%) and drug companysponsored educational seminars $(66 \%) .17 \%$ of students said that if presented with a choice of drugs identical in terms of price, efficacy, and effectiveness, they would prescribe the drug from the company that provided them with financial incentives. Statistical analysis showed no differences in responses among the different years of medical students. There were some differences in responses between medical students who had a doctor parent compared to those who did not have a doctor parent. Medical students are generally not opposed to interacting with or receiving gifts from pharmaceutical companies. Insights gained from this study raises issues that may be of interest to medical educators concerning the attitudes of the future physicians in Canada.
\end{abstract}

KEY WORDS: Medical students, pharmaceutical industry, promotion, marketing, gifts.

\section{BACKGROUND}

There has long been a close relationship between physicians and the pharmaceutical industry. It has been estimated that $85-90 \%$ of doctors in Britain, Canada, New Zealand, and the United States see pharmaceutical company representatives (1). These representatives often visit physician offices to discuss their products,

*To whom correspondence should be addressed: Joseph Barfett email: jjbarfet@uwo.ca provide free samples, and offer gifts. According to industry estimates, pharmaceutical promotional expenditures in the United States amounted to \$21 billion dollars in 2002; approximately $25 \%$ of this amount was spent on detailing to doctors, $4 \%$ on hospital detailing, $2 \%$ on journal ads, $56 \%$ on samples, and $12.5 \%$ on direct-to-consumer advertising (2). Complete spending figures for Canada are not readily available, but one source reported that drug companies spend $\$ 1.7$ billion per year to promote their products to 
doctors in Canada (3).

Many are concerned that drug company marketing poses serious ethical problems that can undermine the physician-patient relationship $(4,5)$. It is felt that physician-industry interactions, including the introduction of incentives by drug companies, may influence physician decision-making and lead to inappropriate prescribing. This potential conflict of interest adds a non-medical dimension to patient care which can do more harm than good.

The first interaction between physicians and the pharmaceutical industry often occurs in medical school. From free pens and lunches, to sponsoring educational seminars and social events, students are inundated with medical "freebies". Critics argue that allowing drug companies to offer gifts to medical students may influence the students' prescribing behaviour when they become physicians (6).

Barnes and Holcenberg conducted one of the first studies of medical student attitudes toward pharmaceutical promotion (7). In their survey of 254 medical students and 59 pharmacy students at the University of Washington, $60 \%$ of the students surveyed favoured a policy statement regarding medical student interactions with drug companies. Contact with drug company representatives during medical school was acceptable to just over $50 \%$ while receipt of noneducation gifts was acceptable to only $28 \%$. Furthermore, about $60 \%$ of the students surveyed felt that promotional practices by drug companies can influence prescribing behaviour.

A more recent study of medical and other health professional students at an American university, by Monaghan and colleagues, found significant deficiencies in student knowledge about pharmaceutical marketing expenditures, professional ethics in interacting with drug companies, and accuracy of drug information from sales representatives (8). The authors concluded that medical schools should do more to educate students about pharmaceutical marketing strategies and how these strategies may affect prescribing behaviour.

Other studies involving medical students show some noteworthy findings. For example, at one US medical school, $85 \%$ of medical students thought it would be inappropriate for politicians to receive a $\$ 50 \mathrm{gift}$, but only $46 \%$ thought it would be inappropriate for a medical student to accept $\$ 50$ from a pharmaceutical company (9). In another study, Finnish medical students were found to have positive attitudes toward drug promotion and favoured promotion activities that gave them material profit, such as books or social events (10). In fact, $70 \%$ of the students thought that drug promotion was necessary.
Little work has been done to explore the attitudes about the receipt of promotional gifts and other incentives by medical students training in Canada. In our review of the current literature, we found only one study that examined the attitudes of Canadian medical students concerning the acceptance of gifts and other forms of physician-industry interactions (11). This initial study by Hodges found that the more money and promotional gifts a physician-in-training (including clinical clerks) had received, the more likely the trainee believed that discussions with representatives did not affect prescribing.

\section{PURPOSE}

The purpose of the present study is to assess the current attitudes of medical students in a Canadian academic centre toward pharmaceutical promotion. Although our work is not the first study to assess the attitudes of Canadian medical students about physicianindustry relations, to our knowledge it is the first in Canada to assess the attitudes of students in different levels of medical training.

\section{METHODS}

A questionnaire was designed to assess the attitudes of medical students at the University of Western Ontario (London, Ontario, Canada) toward pharmaceutical marketing practices. With the approval of the university's Health Sciences Research Ethics Board (HSREB), the survey was administered to first, second, and fourth-year medical students during January and February of 2004. Third-year medical students were not included in the study; this will be further elaborated in the discussion.

We conducted the survey on a day when a series of lectures was scheduled for the entire medical class in the same room. Questionnaires were distributed during the 10 to 15 minute break time between consecutive lecture periods. Three sessions were administered in total, one for each medical class surveyed. At each session, a short presentation was given outlining the purpose of the survey. A letter of information and consent form was also handed out, which explained the study in more detail and the student's right to refuse to participate. The collection of the completed questionnaires was done either during the break or following the next lecture. No incentives were offered for completing the questionnaire.

The questionnaire contained 19 questions, divided into two parts (see appendix). The first part contained 12 questions regarding the acceptability of receiving various gifts from drug companies and student attitudes toward student-industry interactions. These questions were designed to elicit the respondents' personal beliefs 
and test them using hypothetical situations. The responses to 8 of the 12 questions were based on a modified 5-point Likert scale, from 1 (strongly disagree) to 5 (strongly agree). These Likert-type items were analyzed such that scores $<3$ indicated disagreement with a statement, scores equal to 3 indicated neutrality towards a statement, and scores $>3$ indicated agreement with a statement. Responses to 3 of the questions were presented in multiple-choice format. The final item in part one of the survey was an open-ended question asking the respondent to describe their views regarding interactions between medical students and the pharmaceutical industry.

The second part of the survey contained seven questions that collected demographic and socioeconomic data about the responding population, including information on sex, educational background, year of study, medical school, hometown population, annual parental income, and whether or not the respondent had a parent who was a medical doctor. To ensure anonymity, identifying information, such as the respondent's name, was not collected.

Medical student responses to most of the questions were reported as percentages of those surveyed who agreed, disagreed, or were neutral to the statements. To determine statistical differences among subpopulations of students based on demographic and socioeconomic data, desired combination data sets were analyzed using two methods. In the first instance, when the responses of only two subgroups were compared to each other, a t-test was performed with limits based on $95 \%$ confidence (i.e. $\mathrm{p}<0.05)$. In the second case, when more than two subgroups were compared at one time, a one-way ANOVA test was performed, again with limits based on $95 \%$ confidence (i.e. $\mathrm{p}<0.05$ ).

\section{RESULTS}

A total of 202 out of a possible 372 medical students in the first, second, and fourth-year classes completed the survey. This represented an overall response rate of $54 \%$. The response rates for individual questions varied somewhat, so the reported results are based on the data obtained for each question. The demographic profile of the study population is shown in Table 1. More females than males responded to our survey (59\% vs. $40 \%)$. This is different than the actual male-female population of the three medical classes surveyed.

In response to the statement that medical students should not have any interaction with drug companies in medical school, $19 \%$ agreed with the statement, $59 \%$ disagreed with the statement, and $22 \%$ were neutral. In response to the statement that it was unacceptable for a physician to receive a gift from a pharmaceutical company in any form, $23 \%$ of the students agreed with the statement, $49 \%$ disagreed with the statement, and $28 \%$ were neutral. Table 2 displays the survey results regarding medical student attitudes about the acceptability of receiving gifts from a pharmaceutical company.

A question designed to test the effect of drug promotion on the future prescribing practices of medical students showed that when presented with a choice of drugs identical in terms of price, efficacy, and effectiveness, $17 \%$ of the students would prescribe the drug from the company that provided them with gifts or incentives rather than the drug from a company that did not provide gifts or incentives.

The sponsoring of events or educational seminars during medical school was acceptable to $66 \%$ of those surveyed. Also, $50 \%$ of the students said they would not mind the logo of a drug company appearing in the bottom corner of the first slide of every lecture if the company paid for the printing costs of all their class notes in undergraduate medical school.

About $81 \%$ of those surveyed believed that drug companies are primarily interested in profit but still try to work in the best interests of doctors and patients. Approximately $24 \%$ of students agreed with the statement that the information about drug effectiveness from pharmaceutical companies is untrustworthy; $39 \%$ disagreed with the statement, and $36 \%$ were neutral on the subject.

Statistical analysis of medical student subpopulations revealed that, although both males and females were not generally open to accepting expensive gifts that had little or no educational value, males were more agreeable to accepting golf clubs and watches/jewelry compared to females $(\mathrm{p}<0.05)$.

Thirty-five students (17\% of respondents) had at least one parent who was a medical doctor. There were some differences in the way that students with a doctor parent answered compared to those who did not have a doctor parent. For instance, students that did not have a doctor parent were more likely to find it acceptable for drug companies to sponsor events or educational seminars

Table 1. Demographic Profile of Study Population

\begin{tabular}{ll}
\hline Characteristic & No. (and \%)* of respondents \\
\hline Sex & $80(40)$ \\
$\quad$ Male & $119(59)$ \\
Female & \\
& \\
Medical School Year & $66(33)$ \\
First & $83(41)$ \\
Second & $53(26)$ \\
Fourth & \\
\hline
\end{tabular}

*The percentage of respondents was based on the 202 surveys that were submitted. Some students did not answer all of the questions. 
during medical school ( $\mathrm{p}<0.05)$. In addition, students that did not have a doctor parent were more likely to find it acceptable to accept small pharmaceutical company logos on medical school lecture notes if all the printing costs were subsidized by that company ( $\mathrm{p}<$ 0.05).

No significant differences in attitude were found when the respondent groups were compared by criteria such as year of study in medical school, educational background, or annual parental income.

\section{DISCUSSION}

To our knowledge, this survey represents the first in Canada to assess attitudes about pharmaceutical promotion from students in different levels of medical training. The only other study of medical students in Canada about this topic was limited by the small sample of medical students that were surveyed (21 clinical clerks in a psychiatry rotation); students in their preclerkship years (first- and second-year) were not surveyed in the initial study (11).

Student responses to our questionnaire survey present an interesting snapshot of how future physicians in Canada view interactions with the pharmaceutical industry. Overall, students were not opposed to interacting with drug companies in medical school. Only $23 \%$ of the students surveyed felt that students should not have any interaction with drug companies in medical school. Furthermore, only $19 \%$ of students felt that it was unacceptable for a physician to receive a gift from a drug company in any form.

Medical students felt comfortable accepting gifts of minimal value, such as lunches $(75 \%)$ and penlights (74\%), but were willing to accept gifts of higher monetary value if the gifts were of educational benefit, such as textbooks (65\%) and drug company-sponsored educational seminars $(66 \%)$. This idea is further strengthened by the observation that $50 \%$ of the students would not mind accepting lecture notes with the logo of a drug company appearing in the bottom corner of the first slide of every lecture if the company agreed to pay for the printing costs. Stethoscopes and palm pilots, which have educational value and pertain to a physician's work but are of significant monetary value, were viewed as less acceptable (44\% and $26 \%$ respectively). High monetary value gifts with no educational value, such as golf clubs and jewelry/watches, were viewed as least acceptable (15\% and $14 \%$ respectively). These results are in agreement with studies examining physician attitudes toward gifts from drug companies $(12,13)$. For example, Brett and colleagues found that physicians make distinctions about the ethical acceptability of drug company gifts based on the monetary value of the gift (i.e. lower value gifts were more acceptable) and the type of gift (i.e. educational gifts were more acceptable than recreational gifts) (13).

Our results also indicate a prevailing perception among students that the pharmaceutical industry, although driven by profit, still fulfills an important role in enabling physicians to offer treatment to patients in their care. A considerable percentage (39\% of respondents) believed that the pharmaceutical companies generally present accurate information about their products as measured by their claim to effectiveness. This finding may be a concern as some studies suggest that drug information provided by pharmaceutical representatives and drug advertisements are inaccurate $(14,15,16)$. Furthermore, $81 \%$ of students did not rule out interacting with the pharmaceutical industry during the course of their undergraduate medical education (they either agreed or were neutral with the idea). This might indicate that the students believe in their ability to make unbiased decisions despite drug company marketing. However, one must concede that, if the study by Monaghan and colleagues holds true at this medical school, the majority of the undergraduate medical trainees simply do not have the knowledge to fully understand all the nuances of marketing and product promotion (8).

Critics argue that receipt of a gift, no matter how small, is accompanied by a subliminal expectation of

Table 2. Medical Student Attitudes about the Acceptability of Receiving Gifts from a Pharmaceutical Company*

\begin{tabular}{|c|c|c|c|}
\hline \multicolumn{4}{|c|}{ Response to Statement: "I would be comfortable receiving the following gifts from a pharmaceutical company" } \\
\hline Gift & No. $(\%)$ disagree & No. (\%) neutral & No. $(\%)$ agree \\
\hline golf clubs 1 & $46(73)$ & $23(12)$ & $30(15)$ \\
\hline lunch & $27(13)$ & $24(12)$ & $150(75)$ \\
\hline palm pilot & $102(51)$ & $47(23)$ & $52(26)$ \\
\hline penlight & $24(12)$ & $29(14)$ & $148(74)$ \\
\hline stethoscope & $75(37)$ & 37 (18) & $89(44)$ \\
\hline textbook & 39 (19) & $31(15)$ & $131(65)$ \\
\hline watch/jewelry1 & $53(76)$ & $20(10)$ & $28(14)$ \\
\hline
\end{tabular}

*Percentages may not add up to $100 \%$ due to rounding. 
reciprocity $(5,17,18)$. Subliminal advertising, which marketing companies have used for years, is also a concern $(5,13)$. For example, seemingly trivial gifts such as pens, notepads, and calendars, which are conspicuously labeled with drug company logos and brand names of new drugs, may influence a physician's prescribing behaviour. It is encouraging to note, however, that studies have shown educating medical students about the potential dangers of drug company marketing is effective in changing student attitudes toward receiving gifts (19).

Although many medical students may not be too concerned about potential subliminal reciprocity, most are wary of receiving gifts with strings attached; that is, receiving gifts from drug companies in relation to prescribing practices. Only 17\% of students said that if presented with a choice of drugs identical in terms of price, efficacy, and effectiveness, they would prescribe the drug from the company that provided them with financial incentives. While the above scenario may appear benign, it could put physicians in a dangerous situation where they are more vulnerable to future ethical compromises. Furthermore, one can argue that the mere appearance of impropriety might erode trust and undermine the physician-patient relationship.

Our analysis to find differences among subpopulations of students based on demographic and socioeconomic factors showed some interesting results. The survey was conducted at a time during the academic year when the in-hospital training for fourthyear clinical clerks was completed. This allowed us to compare attitudes of students before and after the inhospital training phase of medical school when students may have increased opportunities to interact with drug representatives in the hospital environment. Although we expected to find differences in responses between pre-clerkship students and clinical clerks who completed the in-hospital training component of their medical school education, no statistically significant differences were apparent. The reason for this is unclear. Perhaps clinical clerks do not have increased interaction with drug reps and therefore do not have a corresponding change in attitude toward pharmaceutical promotion practices. Alternatively, clinical clerks may have increased interactions with drug reps, but these interactions do not alter their attitudes about accepting gifts from the pharmaceutical industry. To help clarify these issues, one could design and administer a questionnaire to clinical clerks that elicits information about a student's current interactions with the pharmaceutical companies and their attitude toward accepting promotional gifts, as well as their recollection of pharmaceutical industry interactions and attitudes during their first two years in medical school. This type of retrospective analysis has recently been used by others to study the post-training attitudes and behaviour of internal medicine residents (20).

We also found that students who did not have a doctor parent were more likely to find it acceptable for drug companies to sponsor events and education seminars, and receive subsidized lecture notes compared to those students who had a doctor parent. Why there was a difference in attitude between these two subpopulations is not known. It can be speculated that students with physician parents are somehow influenced while growing up to be less approving about the acceptance of sponsorships and subsidies from drug companies. However, this does not explain why there were no significant differences between the subpopulations when it came to the acceptance of gifts listed in Table 2.

A limitation in this study was the absence of surveyed third-year medical students. We chose not to survey this cohort of students because of logistical reasons and study design. As described in the methods section, we conducted the survey on a day when a series of consecutive lectures was scheduled for the entire medical class. This approach was taken to ensure an optimum response rate at each survey session. Unfortunately, during the timeframe that the survey was administered, third-year medical students were working as clinical clerks in hospitals and clinics both in and out of the city. Third-year students therefore did not have scheduled lectures at which the entire class was in attendance. For these reasons, we decided to exclude this group due to problems in the distribution and collection of the surveys.

Although it may have been possible to survey a portion of the third-year class in one session, we anticipated that the sample size would be too small to be of much significance compared to the other classes surveyed. A small sample size would also increase the chance of a skewed representation, making it difficult to assess the true attitudes of the third-year class. Furthermore, because our questionnaire was designed to be anonymous and intended to be answered only once by a participant, surveying the third-year class in multiple sessions was not pursued. Doing so would increase the risk of a single participant submitting a questionnaire more than once. This would also lead to an inaccurate representation of the third-year class.

Overall, it was found that the respondents' potential actions, when presented with hypothetical situations, were quite consistent with their beliefs. For example, the respondents who were opposed to receiving gifts from drug companies were also less likely to agree to be compensated when prescribing drugs. Those who believed in limiting interactions with drug company representatives during medical school were also less 
likely to accept drug companies paying for the printing costs of lecture notes or sponsoring events. Conversely, those respondents who believed it was acceptable to receive gifts from pharmaceutical companies were also more likely to accept expensive gifts, companysponsored events, and subsidized lecture notes.

The results of this study reveal the general attitudes of medical students at the University of Western Ontario. While it is hoped that the students surveyed at this medical school represent a true cross-section of all medical students in Canada, the actual attitudes of medical students at other schools may vary. Future research could extend the survey to medical students at other teaching centres across Canada to determine if there are differences between the study populations. Another direction for investigation would be to design a prospective study to assess how medical student attitudes change over the course of their training from medical school through residency using pre and posttraining surveys. Other areas of interest might involve taking a closer look at the pharmaceutical industry itself and its strategy for marketing to undergraduate medical students.

\section{CONCLUSIONS}

We found that medical students at the University of Western Ontario are generally not opposed to interacting with or receiving gifts from the pharmaceutical industry. Most students felt comfortable receiving gifts of low monetary value, but were willing to receive gifts of higher value if they served an educational purpose. However, many students may not be aware of the goals of various pharmaceutical marketing strategies and the potential for subliminal reciprocity. Perhaps the insights gained from our study will be used to modify medical curricula to teach students about physician-industry interactions and the danger of potential conflicts of interest. In any case, we hope that our work will stimulate discussion about the issues concerning the relationship between medical students and the pharmaceutical industry.

\section{REFERENCES}

1. Lexchin J. Interactions between physicians and the pharmaceutical industry: What does the literature say? CMAJ. 149(10):1401-1407; 1993.

2. The Physician-Pharmaceutical Industry Relationship. No Free Lunch; Jan 2004. Available:www.nofreelunch.org/ nofreelunchweb4/index.htm (accessed 18 Jul 2004).

3. Square D. Does that free sleeve of golf balls demean the profession? CMAJ. 168(7):884; 2003.

4. Wazana A. Physicians and the pharmaceutical industry: is a gift ever just a gift? JAMA 283:373-380; 2000.

5. Katz D, Caplan A, Merz JF. All gifts large and small: toward an understanding of the ethics of pharmaceutical industry gift giving. Am J Bioethics 3:39-46; 2003.

6. Rogers WA, Mansfield PR, Braunack-Mayer AJ, Jureidini JN. The ethics of pharmaceutical industry relationships with medical students. Med J Aust. 180(8):411-414; 2004

7. Barnes CJ, Holcenberg JS. Student reactions to Pharmaceutical Promotion Practices. Northwest Med. 70:262-266; 1971.

8. Monaghan MS, Galt KA, Turner PD, Houghton BL, Rich EC, Markert RJ, Bergman-Evans B. Student Understanding of the Relationships Between the Health Professionals and the Pharmaceutical Industry. Teaching and Learning in Medicine. 15:14-20; 2003.

9. Palmisano P, Edelstein J. Teaching drug promotion abuses to health profession students. J Med Educ. 55:453-5; 1980.

10. Mantyranta T, Hemminki E. Medical students and drug promotion. Acad Med. 69(9):736; 1994.

11. Hodges B. Interactions with the pharmaceutical industry: experiences and attitudes of psychiatry residents, interns and clerks. CMAJ. 153(5):553-9; 1995.

12. Steinman MA, Shlipak MG, McPhee SJ. Of principles and pens: attitudes and practices of medicine housestaff toward pharmaceutical industry promotions. The American Journal of Medicine. 110:551-557; 2001.

13. Brett AS, Burr W, Moloo J. Are gifts from pharmaceutical companies ethically problematic?: a survey of physicians. Arch Intern Med 163:2213-2218; 2003.

14. Ziegler MG, Lew P, Singer BC. The accuracy of drug information from pharmaceutical sales representatives. JAMA. 273(16):1296-8; 1995.

15. Wilkes MS, Doblin BH, Shapiro MF. Pharmaceutical advertisements in leading medical journals: experts' assessments. Ann Intern Med. 116(11):912-9; 1992.

16. Lexchin J. What information do physicians receive from pharmaceutical representatives? Can Fam Physician. 43:941945; 1997.

17. Chren MM, Landefeld CS, Murray TH. Doctors, drug companies, and gifts. JAMA. 262:3448-3451; 1989.

18. Dana J, Loewenstein G. A social science perspective on gifts to physicians from industry. JAMA 290:252-255; 2003.

19. Vinson DC, McCandless B, Hosokawa MC. Medical students' attitudes toward pharmaceutical marketing: possibilities for change. Family Medicine 25:31-33; 1993.

20. McCormick BB, Tomlinson G, Brill-Edwards P, and Detsky AS. Effect of Restricting Contact Between Pharmaceutical Company Representatives and Internal Medicine Residents on Posttraining Attitudes and Behavior. JAMA 286: 1994-1999; 2001. 
Appendix. The Survey Questions

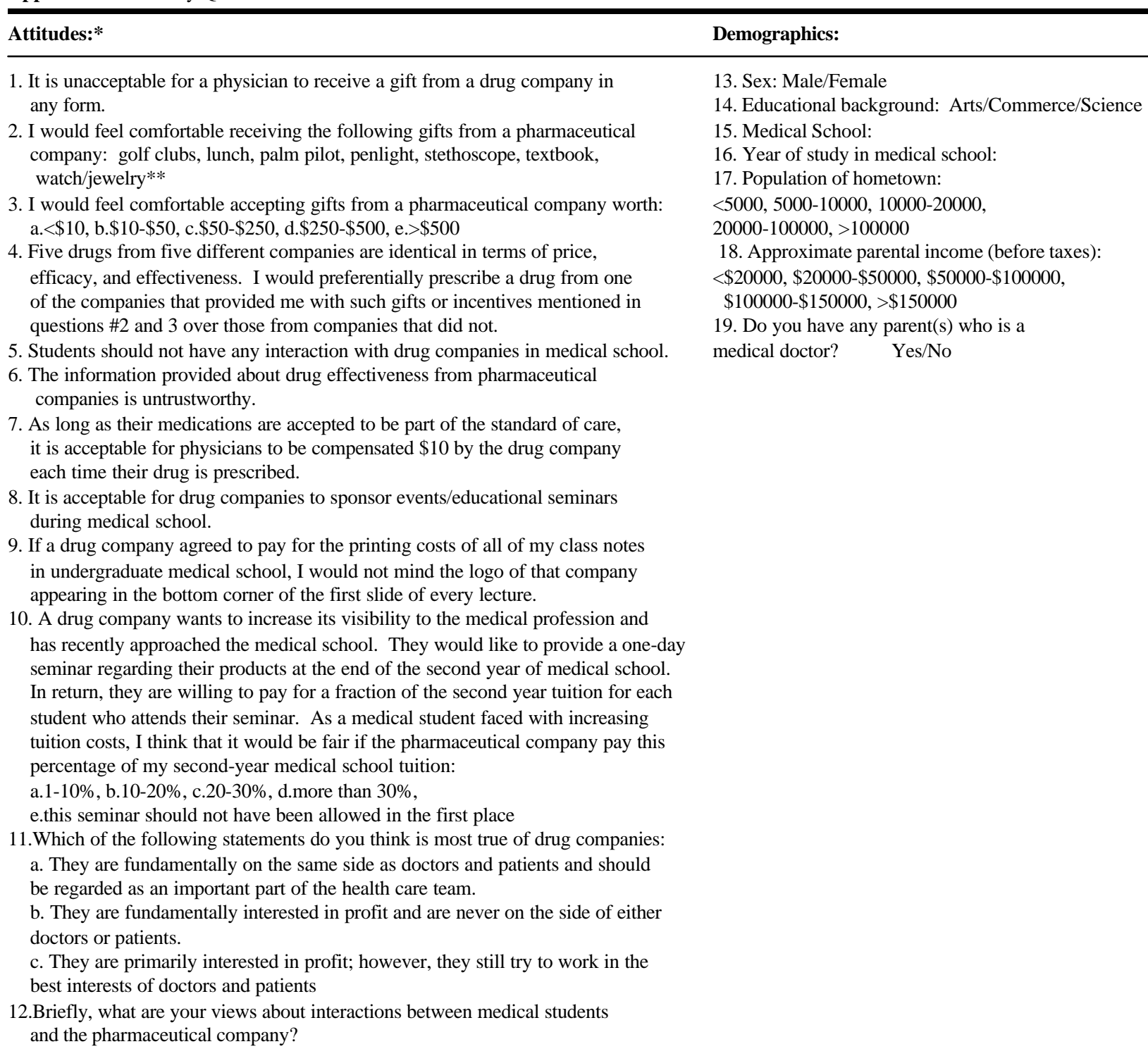

*Respondents answered Questions 1, 2, 4-9 using a modified 5-point Likert scale, from 1 (strongly disagree) to 5 (strongly agree).

Questions 3, 10, and 11 were multiple-choice questions. Question 12 was an open-ended question.

**Each gift in Question 2 was rated individually.

Joe Barfett is a third year medical student at the University of Western Ontario, where he will graduate in 2006 with both a Medical Doctorate and an undergraduate Chemical/Biochemical Engineering Degree through Western's M.D./B.E.Sc. Program. His primary area of research is in neurodegeneration and neuro-oncology and includes work in gene therapy, computational fluid dynamics and nanoscale drug delivery technology.

Brent Lanting is a third year medical student at the University of Western Ontario. He will graduate in 2006 from the faculties of Medicine and Mechanical/Materials Engineering His other research interests include upper limb research.

Julian Lee is a third year medical student of UWO. His area of interest includes research in neuroscience. He obtained a Bachelors of Arts in Psychology from McMaster University and has an M.Sc. in neuroscience at UWO.

Michael Lee is currently a third year medical student at The University of Western Ontario. His interests include research in biostatistics and epidemiology. He obtained an Honours Bachelors of Science in Biochemistry and Chemistry from The University of Western Ontario and a Masters of Science from The University of British Columbia.

Victor Ng is a third year medical student at The University of Western Ontario. His research interests are in the area of respirology and gastroenterology. He obtained an H.B.Sc. in Immunology from the University of Toronto.

Peter Simkhovitch is third year student at the Schulich School of Medicine at the UWO. His interests are in the area of gastroenterology as well as research in the field of diabetes prevention. He obtained his Honours Bachelors of Science from University of Toronto and has worked at the Samuel Lunenfeld Research Institute (Mount Sinai Hospital, Toronto) prior to medical school. During medical school he was a recipient of Ivan H. Smith Memorial Studentship in Radiation Oncology. 